\title{
Qualitative study of the incompatibility of indoor map file formats with location software applications
}

\author{
J. Gelernter ${ }^{1 *}$ (D) and Nishith Maheshwari ${ }^{2}$
}

\begin{abstract}
Indoor maps, and therefore the indoor map data and software that uses them, are used by architects, designers and planners, those in public safety and emergency response, facilities management and even advertising. Presently, the wide range of commonly-used formats for generating indoor maps means that many who would use indoor map applications either must convert indoor map data to another format or re-create the map, which can be time-consuming, costly, and even result in a flawed map. Because the problem is not recognized widely, the benefits that would come from solving it are not widely considered, and so indoor-map related software is not evolving rapidly.

This article brings the problem into focus, which should spur enthusiasm to solve it. The article also considers solutions to interoperability problems, and offers what may be the most expedient solution. The solution, in brief, is that automatic conversion between commonplace indoor map file formats may result in data loss, so encouraging software makers to adopt certain formats is more practical than a solution involving file conversions which will be flawed. This paper advocates for a planned solution to indoor map data incompatibility rather than a market-driven solution which might take years longer to effect.
\end{abstract}

Keywords: Indoor map, Building diagram, Floor plan, Interoperability, File format, IFC, IndoorGML, CityGML, LAS, CAD, KML, SHP, GeoJSON, Data use cycle, Sustainability

\section{Introduction}

\section{Background}

Indoor maps allow us to pinpoint locations in buildings and indoor spaces. Indoor maps are used by architects, engineers and those in the construction industry, government planners and facility managers who operate buildings, managers who track inventory, and the public. Software applications aiding these services must be coupled with maps that include the indoor geometry and labeling of interior spaces. It would be to the advantage of those using map-applications if more maps were available.

\section{Problem}

The variety of geospatial data for GIS applications in general has resulted in data inconsistencies and information loss [14]. This paper focusses on the variety of geospatial

\footnotetext{
* Correspondence: gelern@comminfo.rutgers.edu

${ }^{1}$ Rutgers University, 9726 Fields Road, Gaithersburg, MD 20878, USA

Full list of author information is available at the end of the article
}

data that is indoor $([5,20])$. Some data formats are supported in the import or export options in an application. But in general, the wide range of data formats hinders data integration and re-use. ${ }^{1}$ Pfouga and Stjepandic [13] demonstrate problems arising from the variety of CAD formats-but CAD is only one form of indoor map data. When data is not re-used easily or routinely, the life cycle is not sustainable.

Converting or re-creating map data from an incompatible format for an application can be slow and costly, and the resulting map may suffer data loss. Further, the lack of indoor maps of public buildings creates a barrier to effective emergency operations. In 2015, a LocationBased Services (LBS) Summit to look at these and other problems was held with industry and academic members to determine what should be done first [4]. Improving means to share location was selected as a top priority. This paper addresses that priority. 


\section{Clarification of the problem}

The problem is that the industry depends on a data cycle, from the generation of indoor map data to the use of that data, but with too many data formats, the cycle can be blocked. Hindering the cycle affects those involved -makers of software to generate indoor maps, makers of software that requires indoor maps as input, and also consumers of both types of software. It hurts makers of map generation software because it limits the market; it hurts makers of indoor map application software because limiting data will limit functionality and so it limits this market too; it hurts consumers because limiting the market can limit innovation and keeps prices high.

\section{Definition of indoor map}

Outdoor spatial data is commonly referred to as geographically referenced, or geospatial data [22], and indoor spatial data also can be geographically referenced. ${ }^{2}$ In general, indoor spatial data describes regions within man-made walls above or below the earth's surface. Subway and tunnel maps are considered indoor, too. Plans of building interiors become indoor maps with the addition of absolute coordinates for the surface of the earth. But many indoor floor plans, such as exit diagrams in hotel rooms, do not include absolute coordinates, however, and these are still loosely considered to be indoor maps. A fundamental difference between outdoor and indoor geospatial data is scale: outdoor is small scale and indoor is large scale. The word "map" in the term indoor map suggests to many people that indoor maps can be used for indoor navigation, which is not necessarily the case-unless the file format is suitable.

\section{Indoor maps as 2D or 3D}

Indoor map visualizations are described in (Nossum [11]). Some indoor maps show altitude. For buildings in a 2D map, each floor is generally a separate diagram. While most $2 \mathrm{D}$ or 3D digital indoor maps use dark lines for room walls and indoor/outdoor borders, the map have a very wide range of differences: how to show floor height, location uncertainty, and dimensionality (whether 2D or 3D).

\section{Indoor map symbology}

Most symbols are not widely recognized, so a legend or key is still necessary. The symbol library recently made available by the National Alliance for Public Safety GIS Foundation (NAPSG) is not yet in wide use, so it is not a formally recognized standard. ${ }^{3}$ Many organizations create their own symbols instead of using word label to indicate the location of fire alarm panels, standpipes and so forth.

\section{Indoor map data}

Multiple standards exist presently for 2D and 3D indoor map data (Tables 1 and 2).
Indoor maps may be generated from floor diagrams or building or site plans, for example, or point clouds acquired by 3D laser scanners (see Table 3). The range of ways to create an indoor digital map complicate data sharing because different applications create maps in different file formats.

\section{Review of indoor map file formats and collections}

Many digital collections are of the 2D variety: vector maps in Google Maps (KML format) or OpenStreetMap (OSM format). Site maps for office buildings, college campuses or malls found on advertising or informational websites are often in PDF or image formats. The Micello company has been one of the leading providers of indoor map data worldwide, and it was acquired in 2018 by HERE technologies. Micello became a leading provider owing in part to its business model: it offered free map-making services to customers who wanted indoor digital maps of their premises. Because Micello had created the digital map files, they owned them and could add them to their database, which was one of the largest indoor map collections. The company will create indoor maps from owner-supplied data in a number of output formats, including GeoJSON, SHP, PNG and SVG.

\section{Data interoperability problem in general terms}

Interoperability problems due to overly many data formats plague many fields. One technical solution is to incorporate an ontology that shows semantic equivalency between vocabulary term pairs. Ontologies contain logical connections between terms that are broader or narrower as well as on the same level. Crosswalks and ontologies both aim to show how terms are related, but crosswalks include fewer relationships than ontologies. Some have considered a crosswalk to enhance interoperability of geospatial metadata [21], although it is not a complete solution. Converting from raster to vector format is technically complicated. ${ }^{4}$ ESRI and QGIS have tools to do this, but the process may be time-consuming and the results can be inaccurate.

\section{Research questions}

The core research question concerns how we can improve the data cycle to enhance the industry and its consumers. To answer this, we further analyze the question: Given prevailing 2D and 3D indoor map standards, which standards are being used in indoor map creation software, and which standards are being used in applications that require indoor maps as input? Then we consider a potential solution: Which data format would improve indoor map data file compatibility that would be both academically smart and commercially practical? Our answer is not a data format, but a way to determine which data format(s) should be the industry standard. 
Table 1 Three-dimensional data formats

\begin{tabular}{|c|c|c|c|c|}
\hline & \multicolumn{4}{|l|}{ 3D DATA MODELS } \\
\hline & IFC & CityGML v2 & IndoorGML & LAS \\
\hline Primary Purpose & $\begin{array}{l}\text { IFC is used to describe building } \\
\text { and construction industry data. } \\
\text { It facilitates interoperability } \\
\text { among the architecture, } \\
\text { engineering and construction } \\
\text { industries. }\end{array}$ & $\begin{array}{l}\text { CityGML is an application } \\
\text { schema for Geography } \\
\text { Markup Language v3.1.1. } \\
\text { CityGML is used to reach } \\
\text { a common definition of } \\
\text { elements in a 3D city model. }\end{array}$ & $\begin{array}{l}\text { Indoor GML is used to } \\
\text { represent and allow for } \\
\text { exchange of geoinformation } \\
\text { requred to build and operate } \\
\text { indoor navigation systems. }\end{array}$ & $\begin{array}{l}\text { LAS is the standard file } \\
\text { type for point clouds data. }\end{array}$ \\
\hline $\begin{array}{l}\text { Supporting } \\
\text { Organization }\end{array}$ & BuildingSMART & $\begin{array}{l}\text { Open Geospatial Consortium } \\
\text { (OGC) }\end{array}$ & $\begin{array}{l}\text { Open Geospatial Consortium } \\
\text { (OGC) }\end{array}$ & $\begin{array}{l}\text { American Society for } \\
\text { Photogrammetry and } \\
\text { Remote Sensing (ASPRS) }\end{array}$ \\
\hline $\begin{array}{l}\text { Example of } \\
\text { Software for } \\
\text { Viewing }\end{array}$ & Revit for creating IFC files & $\begin{array}{l}\text { CityGML SpiderViewer, } \\
\text { QGIS, ArcGIS }\end{array}$ & FME & $\begin{array}{l}\text { GIS or photogrammetry } \\
\text { software i.e. ESRI or LAS } \\
\text { Tools }\end{array}$ \\
\hline $\begin{array}{l}\text { Description } \\
\text { of Geometry }\end{array}$ & $\begin{array}{l}\text { Each object such as wall, floor, } \\
\text { window, door is associated } \\
\text { with property } \\
\text { 'IFCSHAPEREPRESENTATION,' } \\
\text { which contains the object's } \\
\text { geometry. }\end{array}$ & $\begin{array}{l}\text { The geometry is represented } \\
\text { in } 5 \text { levels of details } \\
\text { (LOD0 - LOD4) }\end{array}$ & $\begin{array}{l}\text { The geometry may be defined } \\
\text { either by external reference, } \\
\text { where the object is defined } \\
\text { in another dataset } \\
\text { (CityGML or IFC for example) } \\
\text { and referenced in the IndoorGML } \\
\text { file, or by explicit definition } \\
\text { of space cell geometry as } \\
\text { either a 3D solid or a 2D surface. }\end{array}$ & $\begin{array}{l}\text { LAS files store data in tuples } \\
\text { of } x, y \text { and } z \text { data with each } \\
\text { tuple representing a point } \\
\text { in space. The combination } \\
\text { of many tuples in close } \\
\text { proximity can create a } \\
\text { 3D representation. }\end{array}$ \\
\hline $\begin{array}{l}\text { Representation } \\
\text { of Object Location }\end{array}$ & $\begin{array}{l}\text { Multiple local spatial reference } \\
\text { systems (SRS) can be defined } \\
\text { for a file. The information to } \\
\text { convert file into a real world } \\
\text { spatial reference systems is } \\
\text { included within the file. }\end{array}$ & $\begin{array}{l}\text { An SRS is defined for the } \\
\text { file and all the objects that } \\
\text { use that reference system } \\
\text { unless overruled by defining } \\
\text { a local SRS for that particular } \\
\text { object or a set of objects. }\end{array}$ & $\begin{array}{l}\text { An SRS is defined and the } \\
\text { information to convert to a } \\
\text { real world reference system } \\
\text { is included in the file. }\end{array}$ & $\begin{array}{l}\text { An SRS for the points } \\
\text { is defined in the file. }\end{array}$ \\
\hline
\end{tabular}

\section{Research approach and contributions}

Our approach is to demonstrate the problem in the broken cycle for indoor map data. We begin with a qualitative comparison of $2 \mathrm{D}$ and $3 \mathrm{D}$ indoor map file formats that are used most widely (Table 1 ). Chen and Clarke [2] compare an even wider number of indoor map file formats with an excellent chart of standards and formats in their Table 1. By contrast, our research compares the format of files generated by software that creates indoor map files to the format of files input in some software that uses indoor maps. Our contributions are (1) to shed light on the problem and explain how a solution could benefit the entire industry-demonstrating benefits will help spur change, and (2) to present alternative solutions that are technically and economically feasible to improve indoor map data sharing and re-use and suggest how to start now to improve the situation.

\section{Overview of solutions}

The present situation of indoor map format standards proposed by the relevant standards body are not being followed. Even so, there are too many format standards. Which to use? Rather than impose one standard at the risk of losing companies that cannot afford to switch, representatives from both the indoor map data creation and indoor map application software industry could decide collectively, perhaps with the guidance of an independent agency [de jure solution], to determine which standard(s) should be the industry backbone. A market solution in which the format used by the leading company becomes the standard is equally viable, but given the present state of the industry, it will occur slowly. The most practical way to determine the premier indoor map data format would be have a de jure solution-and start now on making the decision.

\section{Overview of paper}

Following this Introduction is the section describing Methods used in this paper. Details of the problem are set out in the section on Results. Discussion of the findings and multiple solutions to the data interoperability problem are raised in the paper's Discussion, and the most practical solution is suggested in Conclusion.

\section{Methods}

This research used methods for descriptive data analysis. Descriptions of indoor map formats and software are taken directly from format and software documentation whenever possible (Tables 1 and 2). We discovered and charted connections among data formats and software applications by analyzing similarities of purpose. This allowed us to interpret the data. Then we assigned categories to software types based on inductive reasoning, looking at commercially-available examples and detecting patterns and similarities (Tables 3 and 4). Finally, to 


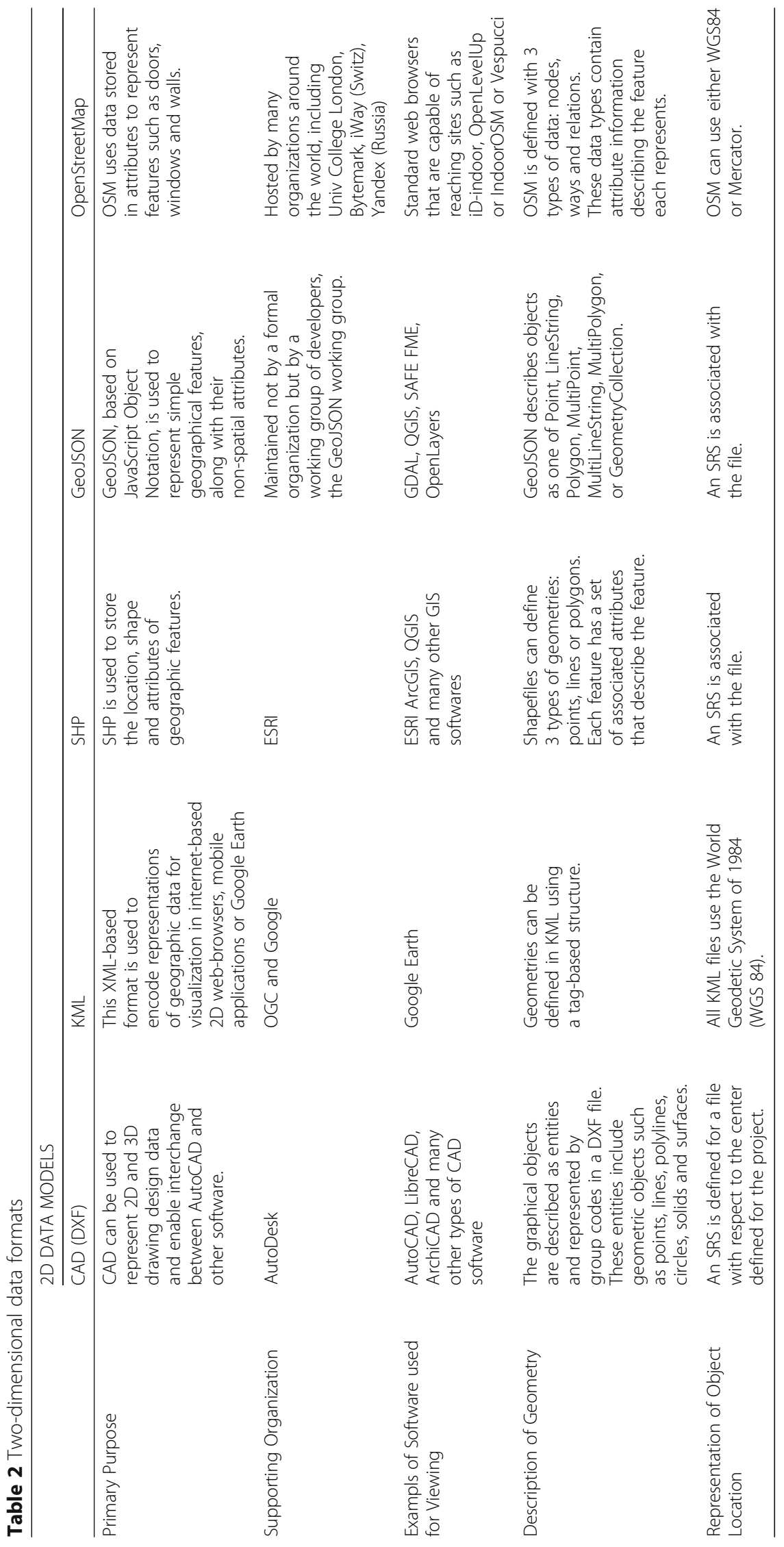




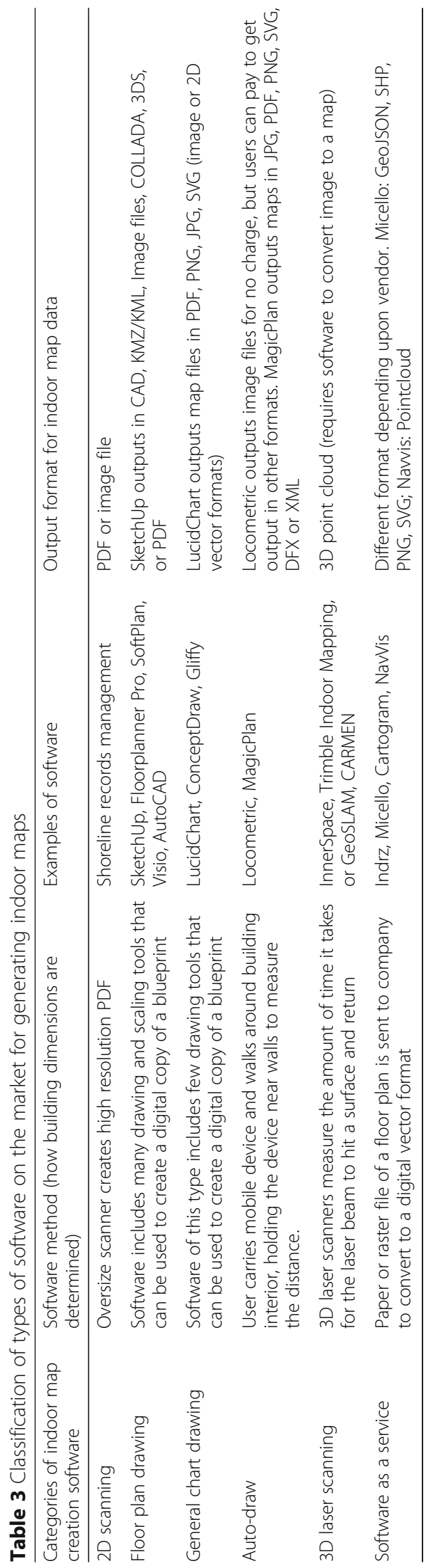


Table 4 Our classification of types of commercially-available software that require indoor map data

\begin{tabular}{|c|c|c|c|}
\hline $\begin{array}{l}\text { Categories of software that } \\
\text { require indoor map as input }\end{array}$ & Software method or purpose & Examples of software & Input format required for indoor map data \\
\hline Emergency response & $\begin{array}{l}\text { Navigation and asset management } \\
\text { (finding people and things) }\end{array}$ & $\begin{array}{l}\text { Preplan View, Firehouse, } \\
\text { eFirstView, Blazemark, } \\
\text { CadZone's The Fire Zone, } \\
\text { Squad Tracker }\end{array}$ & $\begin{array}{l}\text { For Preplan View, use tools that come } \\
\text { with the application to draw your own map }\end{array}$ \\
\hline Indoor navigation & Localization and navigation & $\begin{array}{l}\text { IndoorAtlas, Neon Personnel } \\
\text { Tracker, Infsoft, Accuware, } \\
\text { Spreo, BriteYellow, MazeMap, } \\
\text { MapWIZE }\end{array}$ & $\begin{array}{l}\text { IndoorAtlas does not use an input image, } \\
\text { it creates a map based on an algrothimNeon } \\
\text { Personnel can import a floor plan, but can } \\
\text { also create its own map.InfSoft, Accuware, } \\
\text { Spreao, BriteYellow, MazeMap, and MapWIZE } \\
\text { use floor plans in JPG, PNG or PDF }\end{array}$ \\
\hline Building management & $\begin{array}{l}\text { Creation of data stream regarding } \\
\text { indoor environment, such as } \\
\text { temperature or air pressure }\end{array}$ & Siemens, WRLD & Siemens can use BIM data \\
\hline $\begin{array}{l}\text { Localization, data management } \\
\text { and analytics }\end{array}$ & $\begin{array}{l}\text { Location or tracking of assets, and } \\
\text { analytics on preferences of customers } \\
\text { as taken by tracking customer } \\
\text { foot patterns. }\end{array}$ & $\begin{array}{l}\text { Jibestream, Navvis, Indoo.rs, } \\
\text { Inner Space, MapsIndoors, } \\
\text { Aisle411 }\end{array}$ & $\begin{array}{l}\text { For example, Jibstream converts static maps } \\
\text { of really any format into layered maps. } \\
\text { Navvis and Indoo.rs maps it for you. } \\
\text { Inner Space uses a sensor to make the map. }\end{array}$ \\
\hline
\end{tabular}

examine indoor map file format compatibility we compared data formats in Tables 1 and 2 to the input formats in Table 3 and output formats in Table 4.

Our data sampling method was to include only that software that was commercially available at the time of our study. Applications were excluded from our evaluation if they were in research stages only at the time of writing, such as crowd-sourcing [10] or geo-magnetic positioning [6]. Further, ESRI's ArcGIS Indoors was excluded from analysis because it is only in beta and not commercially available.

Note that our sample was meant to be representative of what is on the market was not intended to be comprehensive. We aimed for breadth, with a sample large enough to suggest that the patterns we found here could be generalized to indoor map formats and applications not described here. Yet, we chose packages that were more common so that the sample would be representative to allow for external validity. Hence, data formats and software omitted should not alter our conclusions appreciably.

\section{Results: Patterns of use regarding indoor map data}

We analyzed indoor map data from three angles: commonly-used file formats for indoor maps, software applications that create or output indoor map data, and applications that require an indoor map base as input.

\section{Indoor map data formats}

The research questions for Tables 1 and 2 were: what are the most commonly-used formats? Are these formats open or proprietary? We included descriptive information about how the formats can be viewed and how they represent objects. The range of formats begins with $3 \mathrm{D}$ and goes to $2 \mathrm{D}$, which is now more common. Software that creates indoor maps and indoor map data providers in most countries are not required to produce maps in any standard file format.

\section{D formats}

The basic criteria for format comparison in Tables 1 and 2 are: Primary purpose of the file format, Supporting organization, Software for viewing, Description of the geometry, and How the location of an object is represented. Commonly-used 3D formats in the USA are IFC, ${ }^{5}$ IndoorGML ${ }^{6}$ and CityGML. ${ }^{7} \mathrm{LAS}^{8}$ is an open format developed to exchange 3D Lidar point cloud data, but useful for any data with $x, y, z$ points. IFC by Building Smart is used by the architecture, engineering and construction industries in Building Information Model (BIM) projects. IndoorGML and CityGML standards developed by the Open Geospatial Consortium both are based on XML grammar [15]. IndoorGML is designed to manage indoor facilities and the use of indoor space, whereas CityGML is used to describe and store spatial information for querying the basic entities of a model of a city. 3D formats are used increasingly in emergency response applications [23].

\section{$2 D$ formats}

Table 2 uses the same criteria as Table 1 so that the 3D and 2D formats can be compared easily. The 2D formats include CAD's DWG/DXF, GeoJSON $,{ }^{9} \mathrm{KMZ} / \mathrm{KML},{ }^{10}$ the proprietary SHP, ${ }^{11}$ as well as image formats (JPG, TIF, and others). The table includes OpenStreetMap even though the IndoorOSM format is no longer in widespread use. ${ }^{12}$ Some of formats store 2D information but include the option of storing 3D, such as DXF format from AutoCAD, the SHP from ESRI, and 3D PDF. ${ }^{13}$ Schemas for the most widely-used 2D formats for indoor mapping-CAD's DWG and DXF, GeoJSON and KML- 
do not include specifications for geospatial information indoors. ESRI developed a tool in 2017 to convert Indoor CAD to a geographic data format. Floor plans might be found in image formats because they were digitized from blueprints on paper, but Table 2 does not include image formats because indoor maps are a minor part of their use. To get an indoor map in KML means creating a vector map in some GIS software and then exporting to KML. IndoorJSON is a variant of GeoJSON that has been used for indoor maps.

\section{Georeferencing and interoperability}

To be considered maps in the narrowest sense, indoor maps need coordinates. GeoPDF and GeoTIFF include georeferencing within the file, as do CityGML. GIS files of buildings including georeferencing, but may not be interoperable with the indoor map formats in Tables 1 and 2 . But many of the 2D and 3D formats in Tables 1 and 2 are used for purposes other than indoor maps, while most raster floor plans from document files (PDF) and image files (PNG, JPEG, and TIFF) need latitude and longitude to be added. How is the georeferencing done? After some latitude and longitude pairs have been recorded, they can be added to the map file. MapTiler or the open source QGIS are some GIS software tools that do this. ${ }^{14}$ Construction of the indoor map with these formats requires recording coordinate pairs for ground control points in building corners, for buildings shaped regularly. More coordinate point pairs will allow for greater precision. Some obvious methods to find coordinates are

- Enter the building address into Google Maps to look up a centroid (or geometrical center) in the middle of the building, in what is called geocoding.

- Overlay or align the floor plan image with an existing map that has known coordinates.

- Align the floor plan outline with a satellite photo that has known coordinates.

- Walk around the building exterior with a GPS device to find coordinates of the building's corners.

Georeferencing is unlikely to impede interoperability because major GIS applications automatically can project data from different coordinate systems into the coordinate system being used. Besides, many location-based service applications that require maps as input (Table 4) tend to need data without georeferencing altogether.

\section{Software to generate indoor maps}

The research questions that produced the Table 3 findings were: What categories of software create indoor maps? How do they actually create the data? What are some examples of commercially-available software in each category? and What map data format does each deliver as output?
We determined several categories of software that make indoor maps in different ways: users drawing the building with drafting-type tools, users drawing just the interior or sketching with drag-and-drop icons for furnishings, users walking inside a building with a sensor in a mobile device so that the space is auto-measured and the map auto-drawn, robots scouting the space and taking sensor measurements to construct a map, or users sending a drawing or digital floor plan to a service company to construct a vector map.

Table 3 only includes methods for which software to construct the map is commercially available at the time of this writing, recognizing that crowdsourcing and magnetic positioning at the time of writing are in research stages. 2D scanning and drawing software rely on pre-existing floor plans; the other categories do not. Only two of the categories--software as a service, and 3D laser scanning--can be used to create maps in vector format which, in turn, can be used by location-based service applications directly. A short overview of the more recent technologies appears in Chow et al. [3]. CARMEN is the open-source software used for robot navigation. The SLAM methods collect indoor locations from the movement of people or robots, and may generate maps that are partial. In the second stage of SLAM, multiple partial maps may be unified into a more accurate 3D map. Unsupervised machine learning techniques such as neural networks then can be used to label rooms, hallways and doors [17]. Otherwise, SimpleIndoorTagging is one tag schema used to label the indoor doors, corridors and areas.

\section{Applications that depend on indoor map data}

The research questions that produced Table 4 findings complement those that produced Table 3 findings: What categories of software require indoor maps as input? What is the overarching purpose of the software in this category? What are some examples of commerciallyavailable software in each category? What map data format does each require as input? Readers are urged to examine column 4 of Tables 3 and 4 carefully because this column shows that most of output formats of map creation software do not coincide with most of the input formats required by applications that use indoor maps. This incompatibility is a main finding of this paper.

Main categories of software in Table 4 proved difficult to differentiate because the software tools for very different purposes often include the same functions. For example, emergency response and shopping both provide for indoor navigation. This section discusses each software category briefly.

\section{Emergency response software}

A main purpose of emergency response applications is to show First Responders how to maneuver around a crisis site, and what assets are where, such as the location of sprinklers, defibrillators, or the nearest fire hydrants. For 
example, Firehouse software and PreplanSource show the location and working status of hydrant water flow, while the Fire Zone and eFirstView can help responders keep track of essential equipment and sensors inside a building.

\section{Indoor navigation software}

Indoor navigation software allows a user to enter a location and the software gives the path or directions to that goal. This is similar to GPS outdoor navigation software. A range of technologies to provide location indoors have emerged because a single technology at present cannot be used inexpensively in all situations. Comparison of technologies and their relative accuracies can be found in Kárník and Streit [7]. In terms of user applications, Infsoft and Spreo focus more on wayfinding by providing step by step directions to the destination along with real-time positioning. Other tools in this category have additional functionality. Accuware keeps track of people inside a building as well as movement of objects outfitted with smart tags, phones or wearable technology.

\section{Building management software}

One purpose of building management software is to provide an overview of an indoor environment given data, for example, from access control or security system, air or water temperature or pressure, or mechanical conditions such as elevator functioning. For example, the WRLD3D system can be used to monitor a building so that when a problem occurs, an engineer unacquainted with the building can be routed to the location of what needs to be fixed. Increased visibility with a Smart Workplace platform involving technology to monitor and analyze the space might turn more attention to workplace maintenance.

\section{Localization, data management and analytics}

Some retail stores are adopting indoor map-related applications to attempt to enhance shopping based on analytics, as from customer foot traffic. Both Aisle411 and Jibestream allow users to search for items in a shopping list and get their aisle whereabouts. Aisle411 can send out location-targeted ads and can provide a 3D augmented view of a store to highlight a daily discount on some shelf. ESRI recently has released ArcGIS Indoors, which at the time of this writing is available only in beta format. ArcGIS Indoors will be a platform on which mappers will be able to assemble indoor data and generate content and services.

\section{Discussion: solutions to indoor map data incompatibility} Our findings (restatement of the problem)

Recall that indoor map data commonly comes in 3D or 2D formats, shown in Tables 1 and 2. For data re-use, these common formats should be output by indoor map creation software (Table 3), and input by indoor map applications (Table 4). However, this is not the case. Indoor map data presently are task, and application-centric. Incompatibility is illustrated in Fig. 1. The point is we found that many indoor map file formats cannot be used widely in location-based service applications.

\section{Problems of interoperability for indoor maps}

Indoor map data should be able to be shared among applications, given appropriate data security measures. The Results section of this paper shows that many categories of indoor map creation software cannot supply maps for indoor location-based services applications due to file format incompatibilities. The consequences of this are (1) for most indoor map creation software, an indoor map is the final output-with re-use of map in other applications impossible, and (2) the majority of indoor location-based services generate their own indoor map input. In short, an indoor map might need to be converted or entirely re-worked in order to upload it to different indoor map applications, even within the same application category (see Table 4).

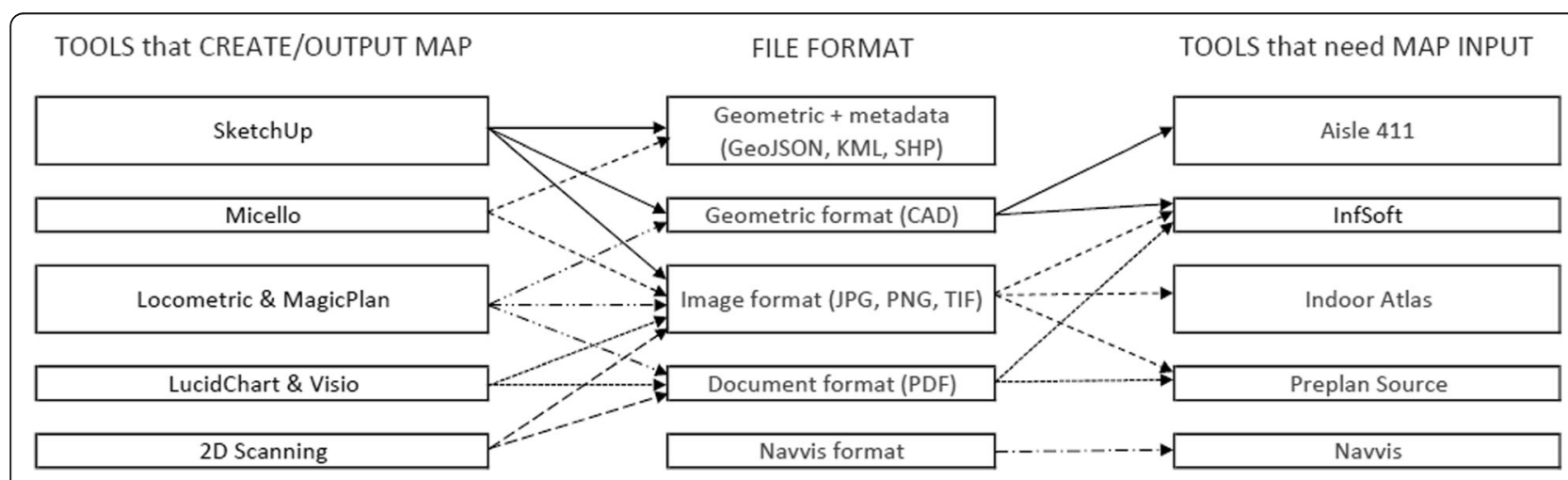

Fig. 1 Illustration of file format incompatibility among a random selection of software tools that create and use indoor maps 


\section{Standardization improves interoperability}

Data and metadata standards help ensure that (in this case, indoor map) data can be reused. A standard file format will need to be modified and maintained over time. Some companies both develop proprietary standards and also submit or support committees to promote an open standard [1]. Organizations that develop geospatial data standards include the international Open Geospatial Consortium (OGC), the International Standards Organization (ISO), and the International Hydrographic Organization (IHO), and in the United States, the Federal Geographic Data Committee (FGDC), the American Society for Photogrammetry and Remote Sensing (ASPRS). Of these, however, recommendations for indoor geospatial standards have come from the Open Geospatial Consortium (OGC). ${ }^{15}$

\section{Interoperability would improve if there were fewer file formats to integrate}

Surveys of indoor location-based service applications reveal the range of data formats used $([5,20]$. The number of file formats in use could be reduced by de jure or de facto methods. A de jure solution would have some independent consortium or standards body developing open standards and advocating for their use. (Multiple standards development bodies can each develop their own standard and advocate for its use.) A de facto solution would result if some possibly proprietary indoor map applications became so widespread that customers and companies would simply adopt those standards.

To review, interoperability can be achieved either through legislating or through the marketplace. In terms of the standard, both open and proprietary have advantages and disadvantages. Open standards are publicly available and can be altered by developers-in fact, so easily altered that the standard becomes too open and is no longer widely interoperable. Proprietary standards are owned by a company and that company can determines who can use it and whether there is a related cost. Open standards increase the size of the marketplace, whereas proprietary standards increase the share of one firm in that marketplace. Note that open standards often are used in open source software. Open source software is more flexible, given the definition of open source, but it likely requires more effort to use, whereas in general the opposite is true for proprietary software.

\section{Technical solution}

Interoperability can be affected not only by data but also at the application or web service level. Using such an application, all formats could translate into a single format. Even so, indoor map data conversion can be inefficient and costly, as well as involve data loss. That is why the focus of this paper is on interoperability at the level of data. Another way to improve interoperability would be to use a data management application to coordinate data use across multiple sites. An example of this for documents (not indoor maps) is the proposed Active Data programming model [18].

Yet another way to improve interoperability would be to re-work applications so that they could accept more data formats. For example, indoor map creation software could provide a 2D file output option such as CAD, and possibly also a 3D output option such as IFC's Building Information Model. 2D CAD and 3D BIM would be suitable choices because these are so widely used by architects and engineers in the United States. Also, BIM is accepted as input in many indoor map applications, which makes it a good choice in a platform to combine with other data types. CAD is more entrenched in the architecture and engineering industries than BIM, however. Alternatively, XML would be a good choice because of relative ease of editing and viewing, with KML for 2D and X3D for 3D, but it is not used as widely, so it would be more costly to change. Recommendation of XML comes from academia rather than industry [16].

The cost of file format conversion hinders a technical solution. Low-cost file transformation would make it easier to collect the indoor maps that emergency response and other applications need to be practically and commercially viable. But file format transformation between indoor map formats can be time consuming (depending on the formats), and therefore unlikely to be at low cost. Automatic conversion from vector to raster map can be trivial. However, automatic conversion from raster to vector maps can be a problem because some of the data from the raster is lost or transferred incorrectly. Broken lines and lost data may be restored manually, but this process is time consuming. And lots of indoor maps are in raster formats such as JPG and PNG, in which the image is represented pixel by pixel. Without converting a raster format to a vector, a raster map that is enlarged will become pixelated and, at some scale, unreadable. Commercially available geospatial file transformation software includes the FME software by Safe. ${ }^{16}$ FME, however, is not easy to use.

The conversion from 2D to 3D presents technical barriers also. At least one open source tool on GitHub can extrude a $2 \mathrm{D}$ building diagram to $3 \mathrm{D} .{ }^{17}$ But because most applications that use indoor building diagrams need to show walls inside buildings, extrusion is not efficient because the software does not know automatically which lines indicate walls and which indicate staircases, for example, and walls and staircases extrude differently.

\section{Data-centric solution: De jure body advocating for standards}

The Open Geospatial Consortium offers resources such as technical documents, training materials, test kits and 
reference implementations to help technology developers and users take advantage of these open standards. But also, the OGC promotes standards by providing certification and branding to support products that are compliant. It also runs events where all vendors use the same test data (called testbed events) to increase interoperability among vendor products. ${ }^{18}$ Referring back to Tables 1 and 2, OGC supports the 2D KML and the 3D CityGML and IndoorGML formats. Recently, OGC has put out a specification for large-scale spatial data called 3D Tiles, with the .json extension, that defines a spatial data structure and a set of tile formats. ${ }^{19}$ 3D Tiles was designed for rendering huge datasets such as for photogrammetry or 3D buildings, and it can be used with a 3D model or a point cloud.

\section{Data-centric solution: De facto market acceptance of standards}

One way that standards become accepted is by widespread use. 2D indoor map formats (see Table 2) dominate presently because most applications use 2D indoor map data as input. Of these, the CAD, KML, SHP and GeoJSON vector formats for indoor maps can be scaled up (that is, transformed to larger scale) and retain map clarity. And of the 2D formats, the CAD formats are used widely in the USA for building diagrams by architects, builders and engineers, while vector formats are suitable also for navigation and localization. Apple is attempting to create a standardized schema for GeoJSON with its Indoor Mapping Data Format (IMDF).

IFC's Building Information Model (BIM) of the 3D formats has a cross-application update feature that makes it suitable for data sharing. In the Netherlands, 3D models are used predominantly for emergency responder training, whereas $2 \mathrm{D}$ models are used in support of actual emergency response operations [23]. The same has been noted in parts of the USA, where Responder training programs use 3D models and actual support of incident continues to rely on $2 \mathrm{D}$.

\section{Implications for data storage}

The format in which the data is created, stored, and made available for others is important for data re-use. That is why we discuss data storage options in relation to interoperability. Shared public collections of indoor maps presently in the U.S. are limited in scope, as witnessed by the indoor map database, Google Indoors. ${ }^{20}$ There are relatively few maps available publicly because some building owners are concerned that sharing floor plans will jeopardize security. Some building floor plans are stored by city administrations, where the buildings must conform to city codes and zoning restrictions. Not every city in the U.S. stores building plans. Hesitancy to share geospatial data at this time is international. One French study found that only $15.7 \%$ of spatial data in France is open access [12].

\section{Aggregated storage}

It makes sense to aggregate indoor map data for the sake of emergency response so that it would be easier for First Responders to access maps in nearby regions that do not happen to be in their jurisdiction. The benefits of aggregating building sensor data for emergency response is well known [19]. Another advantage of aggregated storage is that it would simplify map updating. Buildings change: they might be modified, enlarged, or destroyed by fire. To simplify access for Responders in emergency situations, copies of building maps could be kept in a secured database. Once a map was updated, then all applications that used that map could be notified of the change. Already with the 3D BIM format by IFC, a BIM file update can be sent to all related applications that use a particular file. BIM Web Services can also be used for this purpose. ${ }^{21}$

\section{Storage architecture}

One option for geospatial data storage architecture would be a distributed platform to serve and store different geodata formats, such as the BalticBottomBase project of Gdansk, Poland [8]. In this case, the platform makes the data available in compliance with geographic data sharing standards. Authors Kulesza and Wojcik point out that a file system with geospatial data likely would require external tools, whereas a database could be set up to contain functions that operate on all the spatial data. Another possibility for geospatial storage architecture was presented by [9]. Applications that use indoor maps would still need to allow editing within each application, but widespread indoor map data storage and sharing would represent a convenience to the community of indoor map application developers and users. This explains why, in the paper Introduction, we present an approach to indoor maps that is data centric rather than task (or application) centric

\section{Security}

The onus for security and serving the maps only to authenticated users could be part of the storage design or business model. How might this work? In the U.S., indoor map files could be stored within the Homeland Security Information Network (HSIN), that is part of the Department of Homeland Security. ${ }^{22}$ This is already being done for indoor maps of schools and state buildings for West Virginia. Another option is the pay-for-maps model. This is the case with access to a wider map collection from HERE Technologies, owned by several German car companies.

\section{Vision of the database}

Creation of a national, interoperable "base map" for the USA recommended at the 2015 Location-Based Services 
Summit [4] would solve problems of interoperability, access and updating. The United States Geographical Survey (USGS) presently stores geospatial data that is only outdoor. ${ }^{23}$ Adding indoor data to outdoor Geographic Survey (USGS) or to the Homeland Security Network (HSIN) would allow for cross-agency collaboration and improve resources for public safety nationwide. Moreover, adding indoor map data would create opportunities for research and industry to develop tools that use this data. A global vision of an indoor map database would require an enormous volunteer effort to fill in the gaps worldwide. Otherwise, companies such as HERE will charge for map data access.

\section{Conclusion}

Our qualitative study of indoor map data formats exposed the problem of the incompatibility of formats generated by map creation software and required as input by applications that use indoor maps. This break in the data cycle with barriers to indoor map data re-use is inefficient and costly. Work-arounds using software that translate file formats can result in data loss. Without taking action, the interoperability problem likely will subside over time and a few formats will be selected by the market as dominant. However, because indoor map data is not presently a rich source of revenue, the selection process might take a very long time.

This paper not only exposed the problem but also suggested an actionable solution: namely, that industry leaders meet to select a small number of file formats that will become standard, perhaps with the guidance of an independent standards body that considers file formats of indoor maps body such as the Open Geospatial Consortium (OGC). The Open Geospatial Consortium also could help enforce standards. This de jure solution is fair because it encourages the involvement of companies who will bear the financial burden of data format change.

The result of narrowing the range of data formats should be expanded indoor map resources that make indoor map use applications more functional. The consumer market might well expand so as to have make investment in interoperability worthwhile. Where will the indoor maps be stored? Many building owners and public safety officials would benefit from the ease of maintenance and secured storage of a database, and we suggested a secured storage architecture that could accomplish this. A pay-for-data solution will not be viable for emergency services that are on low budget.

\section{Endnotes}

${ }^{1}$ Wacta, Professor of Architecture at Savannah College of Art and Design, put it like this: She mentions that having GIS data available in BIM would help in site analysis. "With BIM, we work too hard. I send the students to go trace building when the building footprints are already [available]. It's [often on] the city's website, and it's free. Why don't we make the students' lives easier so they can spend more time on design rather than busywork?" [p13] Geodesign Steps Up to Shape the Future, ArcNews, Spring 2018, 40 (2), 12-13

${ }^{2} \mathrm{BIM}$ format is not always geo-referenced.

${ }^{3}$ http://napsg-web.s3.amazonaws.com/symbology/ index.html\#/, accessed June 302019

${ }^{4}$ Some of the technical details are found in the Wikipedia article on vector graphics, https://en.wikipedia.org/ wiki/Vector_graphics\#From_raster

${ }^{5}$ Industry Foundation Classes (IFC) https://technical. buildingsmart.org/standards/ifc, accessed June 302019

${ }^{6}$ IndoorGML http://www.opengeospatial.org/standards/indoorgml, accessed June 302019

${ }^{7}$ CityGML OGC Standard. http://www.opengeospatial. org/standards/citygml, accessed June 302019

${ }^{8}$ LAS documentation at https://www.asprs.org/divisions-committees/lidar-division/laser-las-file-format-exchange-activities, accessed June 302019

${ }^{9}$ GeoJSON Specification. https://geojson.org/, accessed June 302019

${ }^{10} \mathrm{KML}$ (Keyhole Markup Language). http://www.opengeospatial.org/standards/kml, accessed June 302019

${ }^{11}$ https://www.esri.com/library/whitepapers/pdfs/shapefile.pdf, accessed June 302019

${ }^{12}$ The OpenStreetMap wiki on IndoorOSM declares that the format is defunct. IndoorOSM can be edited with iD-Indoor, viewed with OpenLevelUp, and is interoperable with OSM (OpenStreetMap) See https://wiki. openstreetmap.org/wiki/Proposed_features/IndoorOSM, accessed June 302019

${ }^{13}$ http://www.3dpdfconsortium.org, accessed June 30 2019

${ }^{14}$ MapTiler on June 302019 at https://www.maptiler. com/, QGIS on June 302019 at https://www.qgis.org/ en/site/. The open source version of MapTiler, TileMill, does not have this capability as of February 2019.

${ }^{15}$ www.opengeospatial.org, accessed June 30, 2019

${ }^{16} \mathrm{https}$ ://www.safe.com as of June 302019

${ }^{17}$ https://github.com/nortikin/prokitektura-blender, accessed June 302019

${ }^{18} \mathrm{http}: / /$ www.opengeospatial.org/compliance, accessed June 302019

${ }^{19} \mathrm{http} / / /$ www.opengeospatial.org/standards/3DTiles, accessed June 302019

${ }^{20}$ https://www.google.com/maps/about/partners/ indoormaps/, accessed June 302019

${ }^{21}$ https://www.nibs.org/page/bsa_bimsie\#examples, accessed June 302019

${ }^{22}$ Based on a June 2017 telephone conversation with Homeland Security Information officer, Jim Mackin.

${ }^{23}$ See the National Map Data Viewer, accessed June 30 2019, https://www.usgs.gov/core-science-systems/ngp/ tnm-delivery/, accessed June 302019 


\section{Abbreviations}

2D / 3D: Two-dimensional space / Three-dimensional space;

ASPRS: American Society for Photogrammetry and Remote Sensing; CAD (dwg/dxf): DWG and DXF are proprietary Computer Aided Design data file formats developed by AutoDesk software and are the most widely used CAD file formats. Documentation URL: https://www.autodesk.com/products/dwg and https://knowledge.autodesk.com/support/autocad/learn-explore/caas/ CloudHelp/cloudhelp/2019/ENU/AutoCAD-Core/files/GUID-D4242737-58BB47A5-9B0E-1E3DE7E7D647-htm.html accessed June 30, 2019;

CityGML: CityGML is an open data model for the storage and exchange of virtual 3D city models. It is implemented as an application schema for Geography Markup Language (GML). Documentation: https://www. opengeospatial.org/standards/citygml, accessed June 30, 2019; FGDC: Federal Geographic Data Committee; GeoJSON: Open standard format designed to represent geographical features. Documentation URL: https://geojson.org/, accessed June 30 2019; GML: Geography Markup Language is a modelling language as well as an interchange format in XML defined by the Open Geospatial Consortium to express geographical features. Documentation https://www.opengeospatial.org/standards/gml, accessed June 30, 2019; IFC: Industry Foundation Class data models are used to describe buildings. Documentation URL: https://technical.buildingsmart.org/standards/ifc, accessed June 30 2019; IHO: International Hydrographic Organization; ISO: International Standards Organization, a standards body with representatives from various standards organizations worldwide; JPG/ JPEG: Joint Photographic Experts Group file format: The group created this raster file format, with the file extension .jpg; KML: Keyhole Markup Language is an XML notation to annotate and visualize geographic features in either two- or three-dimensional Google Earth browsers. Documentation URL: https://www.opengeospatial.org/standards/kml/; LAS: 3-dimensional file format storing $x, y, z$ data in tuples for point clouds. Documentation URL: https://www.asprs.org/divisions-committees/lidar-division/laser-las-file-formatexchange-activities; NAPSG: National Alliance for Public Safety Foundation https://www.napsgfoundation.org/; OGC: Open Geospatial Consortium, an international organization creating geospatial standards; OSM: Open Street Map file format is a vector format used for a world map. Volunteer mappers all over the world have contributed points of interest of a general nature, or for special interests such as sports, history, or wheelchair access.

Documentation URL: https://www.openstreetmap.org/about, accessed June 30 2019; PNG: Portable Network Graphics format; SHP: Shapefile is a geospatial vector data format by the ESRI company. Documentation URL: https://www.esri.com/library/whitepapers/pdfs/shapefile.pdf, accessed June 30 2019; SRS: Spatial Reference System, a local, regional or global coordinate system used to locate entities; TIFF: Tagged Image File Format, used for raster graphics; XML: Extensible Markup Language rules are used to encode documents in a way that is both human and machine-readable

\section{Acknowledgments}

We appreciate the encouragement of Vihang Jani, NIST Colorado, during the early stages of this research. We appreciate also the help of Andrew Sussman in the final preparations of the manuscript.

\section{Authors' contributions}

JG designed the study, helped analyze and interpret the data, and wrote the manuscript. NM collected, analyzed and interpreted the data. The authors approve of the final manuscript.

\section{Funding}

Some of this research was supported by a grant from Public Safety Communications Research (PSCR). The supporter had no role in the study design, or in the collection, analysis or interpretation of the data, or the writing of the manuscript.

\section{Availability of data and materials}

There are no data sets associated with this manuscript. Indoor map file formats analyzed for this article appear in Tables 1 and 2. Software analyzed for this article appears in Tables 3 and 4 . Weblinks to file formats and software referred to in the paper appear in the footnotes.

\section{Competing interests}

The authors have approved the paper, and we have no competing interests. The paper has not been published elsewhere.

\section{Author details}

${ }^{1}$ Rutgers University, 9726 Fields Road, Gaithersburg, MD 20878, USA. ${ }^{2}$ Lab for Spatial Informatics, International Institute of Information Technology, Hyderabad, India.

Received: 7 January 2019 Accepted: 27 May 2019

Published online: 12 August 2019

\section{References}

1. Aggarwal N, Dai Q, Walden EA. Do markets prefer open or proprietary standards for XML standardization? An event study. Int J Electron Commerce. 2006;11(1):117-36.

2. Chen J, Clarke KC. Modeling standards and file formats for indoor mapping. In: Ragia L, Rocha JG, Laurini R, editors. GISTAM 2017: proceedings of the 3rd international conference on geographic information systems theory, applications and management, Porto, Portugal, 27-28 April 2017, SciTe Press, vol. 2017. p. 268-75.

3. Chow JCK, Peter M, Scaioni M, Al-Durgham M. Indoor tracking, mapping, and navigation: algorithms, technologies, and applications. J SENSORS. 2018: 3. https://doi.org/10.1155/2018/5971752.

4. Feldman $H$, McElvaney $T$. Location-based services R\&D summit. NIST technical note 1914: National Institute of Standards and Technology, U.S. Department of Commerce; 2016. https://doi.org/10.6028/NIST.TN.1914.

5. Gunduz $M$, Isikdag U, Basaraner M. A review of recent research in indoor modelling and mapping. In: 23 ISPRS congress, INT ARCH PHOTOGRAMM REMOTE SENS and SPATIAL INF SCI, XLI-B4; 2016. p. 289-94.

6. Huang H, Li W, Luo A, Qui DW, Gao Y. An improved particle filter algorithm for geomagnetic indoor positioning. J Sensors. 2018. https://doi.org/10. $1155 / 2018 / 5989678$

7. Kárník J, Streit J. Summary of available indoor location techniques. IFACPapersOnLine. 2016;49(25):311-7.

8. Kulesza P, Wójcik M. Platform for storing and searching different formats of spatial data. In: Kozielski S, et al., editors. In: BDAS 2014: proceedings of the 10th international conference: beyond databases, architectures and structures, 27-30 may, Ustroń, Poland, Communications in Computer and Information Science, vol. 424; 2014. p. 444-53.

9. Li Q, Guo L, Tu Y, Huang F. An integrated geospatial metadata storing architecture. In: IGARSS 2004: IEEE international geoscience and Remote sensing symposium, 20-24 September, Anchorage, AK, vol. 7; 2004. p. 4425-7.

10. Mazumdar P, Ribiero VJ, Tewari S. Generating indoor maps by crowdsourcing positioning data from smartphones. In: IPIN 2014: international conference on indoor positioning and indoor navigation 2730 October 2014, Bexco, Busan, Korea; 2014. p. 322-31.

11. Nossum AS. Developing a framework for describing and comparing indoor maps. Cartogr J. 2013;50(3):218-24.

12. Noucher M, Gourmelon F, Gautreau P, Georis-Creuseveau J, Maulpoix A, Pierson J, Pinède N, Pissoat O, Rouan M. Spatial Data Sharing: A Pilot Study of French SDIs International. J Geo-Information. 2017;6(99):1-23.

13. Pfouga A, Stjepandic J (2015) leveraging 3D CAD data in product life cycle: exchange - visualization - collaboration. Transdisciplinary lifecycle analysis of system in: R. Curren et al (eds) ISPE 2015: proceedings of the 22nd international conference on concurrent engineering, 20-23 July 2016, Delft, Netherlands. Advances in Transdisciplinary Engineering vol 2, pp 575-584.

14. Rana TA, Komesli M, Ercan T, Sun Y. Integration of GIS: a showcase study on GML based WebGIS. In: Liu L, Li X, Liu K, Zhang X, Chen A, editors. Geoinformatics 2008 and joint conference on GIS and building environment: geo-simulation and virtual GIS environments. Guangzhou, China. Proceedings of SPIE, the International Society for Optical Engineering, vol. 7143; 2008. p. 8.

15. Ryoo HG, Kim T, Li KJ. Comparison between two OGC standards for indoor space: CityGML and IndoorGML. In: ISA '15: Proceedings of the Seventh ACM SIGSPATIAL International Workshop on Indoor Spatial Awareness, 3-6 November 2015. Seattle, WA: USA ACM; 2015. p. 8. https://doi.org/10.1145/ 2834812.2834813.

16. Sandström H, Svenson J. Indoor maps. Master's Thesis. Stockholm, Sweden: Royal Institute of Technology; 2010.

17. Sedelmeier A, Feld S. Discovering and learning recurring structures in building floor plans. In: Kiefer P, Huang H, Van de Weghe N, Raubal M, editors. LBS 2018: 14th International conference on location-based services, 
15-17 January 2018, Zurich, Switzerland, Lecture Notes in Geoinformation and Cartography: Springer, Cham; 2018. p. 151-70.

18. Simonet A, Fedak G, Pipeanu M, Al-Kiswany S. Active data: A data-centric approach to data life-cycle management. In: PDSW '13: Proceedings of the 8th Parallel Data Storage Workshop 17-21 November. Denver Colorado, USA: ACM Publishers; 2013. p. 39-44.

19. Wang X, Walden A, Weigle M, Olariu S (2014) Strategies for sensor data aggregation in support of emergency response. In IEEE MILCOM: Military Communications Conference, 6-8 October. Baltimore, MD, USA., p $1120 \mathrm{ff}$.

20. Werner M. Indoor location-based services: prerequisites and foundations. Switzerland: Springer International Publishing; 2014.

21. Yang H, Feng G (2012) Automatic creation of crosswalk for geospatial metadata standard interoperability In Xiao, N et al (eds) GIScience 2012: 7th International Conference Geographic Information Science, 18-21 September, Columbus, OH, USA, Lecture Notes in Computer Science vol 7478, Springer Heidelberg, pp 311-324.

22. Yeung AKW, Hall GB. Spatial database systems: design, implementation and project management. GEOJ LIB. 2007;87.

23. Zlatanova S, Stoter J, Isikdag U. Standards for exchange and storage of 3D information: challenges and opportunities for emergency response. In: Bandrova T, Konecy M, Zhelezov G, editors. ICCGIS 2012: proceedings of the 4th international conference on cartography \& GIS, Sofia, Bulgaria, vol. 2, Albena; 2012. p. 17-28.

\section{Publisher's Note}

Springer Nature remains neutral with regard to jurisdictional claims in published maps and institutional affiliations.

\section{Submit your manuscript to a SpringerOpen ${ }^{\mathcal{O}}$ journal and benefit from:}

- Convenient online submission

- Rigorous peer review

- Open access: articles freely available online

High visibility within the field

- Retaining the copyright to your article

Submit your next manuscript at $\boldsymbol{\nabla}$ springeropen.com 